\title{
Correction to: Modulation rate transfer functions from four species of stranded odontocete (Stenella longirostris, Feresa attenuata, Globicephala melas, and Mesoplodon densirostris)
}

\author{
Adam B. Smith ${ }^{1,2}$. Aude F. Pacini ${ }^{1,2}$ - Paul E. Nachtigall ${ }^{1,2}$ \\ Published online: 29 April 2021 \\ (c) Springer-Verlag GmbH Germany, part of Springer Nature 2021

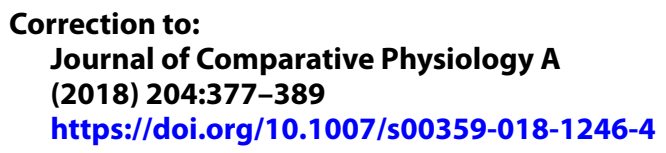 \\ Unfortunately, the $\mathrm{x}$-axis of Figure 6 is labelled with incor- \\ rect units. The correct axis label is "Frequency (Hz)". \\ Furthermore, the maximum $x$-axis value of the lower left \\ panel in Figure 6 should be a value of " 2000 ".
}

Publisher's Note Springer Nature remains neutral with regard to jurisdictional claims in published maps and institutional affiliations.

The original article can be found online at https://doi.org/10.1007/ s00359-018-1246-4.

Adam B. Smith

adambsmi@hawaii.edu

1 Department of Biology, University of Hawai 'i At Mānoa, 2538 McCarthy Mall, Edmondson Hall Room 216, Honolulu, HI 96822, USA

2 Hawai 'i Institute of Marine Biology, 46-007 Lilipuna Road, Kāne'ohe, HI 96744, USA 